\title{
Analysis of the genetic diversity of super sweet corn inbred lines using SSR and SSAP markers
}

\author{
W.R. Ko ${ }^{1 *}$, K.J. Sa ${ }^{1 *}$, N.S. Roy ${ }^{3}$, H.-J. Choi ${ }^{2}$ and J.K. Lee ${ }^{1}$ \\ 1Division of Bio-Resource Sciences, College of Agriculture and Life Science, \\ Kangwon National University, Chuncheon, Korea \\ ${ }^{2}$ Gyeongsangbuk-do Agricultural Research and Extension Services, Daegu, Korea \\ ${ }^{3}$ Department of Molecular Biosciences, Kangwon National University, Chucheon, \\ Korea \\ *These authors contributed equally to this study. \\ Corresponding author: J.K. Lee \\ E-mail: jukyonglee@kangwon.ac.kr \\ Genet. Mol. Res. 15 (1): gmr.15017392 \\ Received August 7, 2015 \\ Accepted October 16, 2015 \\ Published January 22, 2016 \\ DOI http://dx.doi.org/10.4238/gmr.15017392
}

ABSTRACT. In this study, we compared the efficiency of simple sequence repeat (SSR) and sequence specific amplified polymorphism (SSAP) markers for analyzing genetic diversity, genetic relationships, and population structure of 87 super sweet corn inbred lines from different origins. SSR markers showed higher average gene diversity and Shannon's information index than SSAP markers. To assess genetic relationships and characterize inbred lines using SSR and SSAP markers, genetic similarity (GS) matrices were constructed. The dendrogram using SSR marker data showed a complex pattern with nine clusters and a GS of $53.0 \%$. For SSAP markers, three clusters were observed with a GS of $50.8 \%$. Results of combined marker data showed six clusters with $53.5 \%$ GS. To analyze the genetic population structure of SSR and SSAP marker data, the 87 inbred lines were divided into groups I, II, and admixed based on the membership probability threshold of 0.8 . Using combined marker data, the population 
structure was $\mathrm{K}=3$ and was divided into groups I, II, III, and admixed. This study represents a comparative analysis of SSR and SSAP marker data for the study of genetic diversity and genetic relationships in super sweet corn inbred lines. Our results would be useful for maize-breeding programs in Korea.

Key words: Super sweet corn; Genetic diversity; Genetic relationship; Population structure; SSR and SSAP markers

\section{INTRODUCTION}

Maize (Zea mays L.), also known as corn, is mainly used as food for humans and forage for animals. It is classified into normal, waxy, sweet, and popcorn types, among which sweet corn has special characteristics such as sweet taste, thin pericarp, endosperm with delicate texture, and high nutritional value (Kwiatkowski and Clemente, 2007). In addition, for sweet corn for fresh market, freezing and canning has become an important commodity in many countries (El-Hamed et al., 2011). Among the sweet corn varieties, super sweet corn is a homozygous hybrid carrying the shrunken2 (sh2) gene (Tracy, 2001). It has about three times more sugar in the kernel at "roasting ear" stage than the standard sweet corn (su) (Lee et al., 1987), and maintains a good eating quality because the change of sugar into starch after harvest is slow (Marshall and Tracy, 2003). However, particularly in Korea, waxy corn (wx) is more popular to farmers and consumers than sweet corn, because super sweet corn has many disadvantages such as low germination, weak seedling vigor in cold condition, poor uniformity, and expensive seed costs (Azanza et al., 1996; Hassell et al., 2003). Nevertheless, super sweet corn is becoming increasingly attractive in Korea. This change in consumers taste indicates the need to breed new cultivars without undesirable traits.

The traditional breeding method of phenotypic selection in the field is laborious and timeconsuming for developing a new super sweet corn cultivar (Duvick et al., 2004). Phenotypic selection is important for the development of an elite inbred line and for planning crosses in outcrossing plants like corn. However, phenotypic traits are influenced by environmental factors. In contrast, molecular markers are not and can be used to detect genetic diversity among inbred lines and to predict hybrid performance and heterosis (Kashiani et al., 2012; Solomon et al., 2012). An important aspect of hybrid and inbred line development is having information about the genetic diversity and the genetic relationship among inbred lines. This not only helps breeders choose appropriate parental lines but also protects plant variety lines (Hallauer et al., 1988; Pejic et al., 1998). Laborintensive conventional methods have limitations for assessing genetic diversity and genetic relationships among inbred lines owing to environmental interaction, as well as other factors. The use of molecular markers helps to overcome these limitations. Many researchers have attempted to estimate genetic diversity and relationships using various molecular markers such as restriction fragment length polymorphism (Melchinger et al., 1992), amplified fragment length polymorphism (Russell et al., 1997), single nucleotide polymorphism (Dao et al., 2014), and simple sequence repeat (SSR) (Wang et al., 2008). Among these markers, SSR or microsatellites, which are short sequences containing tandem repeated copies of 1-6 nucleotide fragments (Rafalski et al., 1996), are considered one of the most suitable markers for assessing genetic diversity among maize inbred lines. They have the advantage of having a high level of allelic variation, reliability, reproducibility, and discrimination (Enoki et al., 2002). In addition, transposable element-based molecular markers 
have been recently successfully applied for accessing the genetic diversity of many plants (Roy et al., 2015). Several types of transposable element-based molecular markers have been developed from retrotransposons, including retrotransposon-based insertion polymorphisms (RBIP) (Paux et al., 2010), inter-retrotransposon amplified polymorphism (IRAP) (Kalendar et al., 1999), retrotransposonmicrosatellite amplified polymorphism (REMAP) (Kalendar and Schulman, 2006), and sequence specific amplified polymorphism (SSAP) (Waugh et al., 1997). These markers have been used in genetic analyses such as genetic diversity (Jing et al., 2010) and phylogenetic analyses (Vitte et al., 2004). Among the retrotransposon-based molecular markers, SSAP markers amplify the region between a transposon insertion using an oligonucleotide primer on the long-terminal repeat (LTR) of the retrotransposon and an adjacent restriction site (Mardi et al., 2011). They are also used to estimate genetic diversity and relationship because of their higher level of polymorphism and high abundance (Tam et al., 2005; Biswas et al., 2011; Mardi et al., 2011).

The Korean Gyeongsangbuk-do Agricultural Research and Extension Services have maintained and are developing a large number of inbred lines. Since these have not been or are rarely utilized in breeding programs, genetic analysis is necessary to ensure the long-term success of super sweet corn breeding in Korea. Up to date, very few systematic studies on the genetic diversity and relationships among super sweet corn inbred lines have been conducted. The objective of the present study is not only to investigate the genetic diversity and genetic relationships of 87 super sweet corn inbred lines using SSR and SSAP markers, but also to analyze their population structure. In addition, this study aims to compare the use of the two markers, SSR and SSAP, for diversity and relationship analysis.

\section{MATERIAL AND METHODS}

\section{Plant materials and DNA extraction}

Table 1 shows the 87 super sweet corn inbred lines evaluated in this study and their developed derivations. With the goal of developing a new super sweet corn cultivar and new inbred lines, 42 inbred lines were developed directly from Jubilee, a well-known super sweet corn variety (Jubilee group), and 45 inbred lines were developed from a cross between sh and wx varieties (sh/wx group). These breeding materials were maintained at the Korean Gyeongsangbuk-do Agricultural Research and Extension Services. Maize genomic DNA was extracted from young leaves following the protocol of Dellaporta et al. (1983), with minor modifications.

\section{SSR and SSAP analyses}

SSR amplifications were conducted in a total volume of $30 \mu \mathrm{L}$ and consisted of $20 \mathrm{ng}$ genomic DNA, 1X PCR buffer, $0.3 \mu \mathrm{M}$ forward and reverse primers, $0.2 \mathrm{mM}$ dNTPs, and $1 \mathrm{U}$ Taq polymerase (Biotools, Valie de Tobalina, Madrid, Spain). The PCR profile consisted of 5 min initial denaturation at $94^{\circ} \mathrm{C}$, two cycles of 1 min denaturation at $94^{\circ} \mathrm{C}, 1 \mathrm{~min}$ annealing at $65^{\circ} \mathrm{C}$, and 2 min extension at $72^{\circ} \mathrm{C}$. After the second cycle, the annealing temperature was decreased by $1^{\circ} \mathrm{C}$ increments every two cycles until a final temperature of $55^{\circ} \mathrm{C}$ was reached. The last cycle was then repeated 20 times. Upon completion of the cycles, the extension cycle was extended for $10 \mathrm{~min}$ at $72^{\circ} \mathrm{C}$.

For SSAP, primers were derived from the copia-type retrotransposon families Opie and Ji. DNA $(1 \mathrm{mg})$ was digested with the restriction enzyme EcoRI (5 U). A ligation mix consisting of EcoRI adap- 
tors and T4 DNA ligase was then added. The total mixture was diluted 4 times and $3 \mu \mathrm{L}$ was used as template for preamplification using the LTR primers as forward primers and the EcoRI adaptor-specific primer as reverse primer (5'-GACTGCGTACCAATTC-3'). The PCR program was $94^{\circ} \mathrm{C}$ for $3 \mathrm{~min}, 30$ cycles of $94^{\circ} \mathrm{C}$ for $30 \mathrm{~s}, 55^{\circ} \mathrm{C}$ for $30 \mathrm{~s}$, and $72^{\circ} \mathrm{C}$ for $1 \mathrm{~min}$, and a final extension cycle of $72^{\circ} \mathrm{C}$ for $5 \mathrm{~min}$. Amplified products ( $3 \mu \mathrm{L}$ after 100X dilution) were re-amplified using the LTR primers as forward and the EcoRI adaptor-specific selective primer as reverse primer (5'-GACTGCGTACCAATTC+NNN-3'). The PCR program was the same as described above but comprised only 25 cycles.

Table 1. Derivation of 87 super sweet corn inbred lines used in this study.

\begin{tabular}{|c|c|c|c|c|c|}
\hline Entry No. & Pedigree & Sources & Entry No. & Pedigree & Sources \\
\hline ksh3 & 12 wsh $1-3$ & Jubilee & ksh52 & $12 \mathrm{w} 10 \mathrm{~B}-3$ & Progeny of sh/wx cross \\
\hline ksh4 & 12 wsh $1-4$ & Jubilee & ksh53 & $12 \mathrm{w} 10 \mathrm{~B}-4$ & Progeny of sh/wx cross \\
\hline ksh5 & 12wsh $1-5$ & Jubilee & ksh54 & $12 \mathrm{dm} 1-2$ & Progeny of sh/wx cross \\
\hline ksh6 & 12 wsh $1-6$ & Jubilee & ksh55 & $12 \mathrm{dm} 2-2$ & Progeny of sh/wx cross \\
\hline ksh7 & 12wsh 1-7 & Jubilee & ksh56 & $12 \mathrm{dm} 3-1$ & Progeny of sh/wx cross \\
\hline ksh8 & 12wsh 1-8 & Jubilee & ksh58 & $12 \mathrm{dm} 5-1$ & Progeny of sh/wx cross \\
\hline ksh11 & 12 wsh $2-2$ & Jubilee & ksh59 & $12 \mathrm{dm} 6-1$ & Progeny of sh/wx cross \\
\hline ksh12 & 12 wsh $2-3$ & Jubilee & ksh60 & $12 \mathrm{dm} 6-3$ & Progeny of sh/wx cross \\
\hline ksh13 & 12 wsh $2-4$ & Jubilee & ksh61 & $12 \mathrm{dm} 8-1$ & Progeny of sh/wx cross \\
\hline ksh14 & 12 wsh $2-5$ & Jubilee & ksh62 & $12 \mathrm{dm} 9-1$ & Progeny of sh/wx cross \\
\hline ksh15 & 12 wsh $2-6$ & Jubilee & ksh63 & $12 \mathrm{dm} 10-2$ & Progeny of sh/wx cross \\
\hline ksh16 & 12wsh 3-1 & Jubilee & ksh64 & $12 \mathrm{dm} 14-1$ & Progeny of sh/wx cross \\
\hline ksh18 & 12 wsh 3-3 & Jubilee & ksh65 & $12 \mathrm{dm} 16-2$ & Progeny of sh/wx cross \\
\hline ksh19 & 12 wsh 4-1 & Jubilee & ksh66 & $12 \mathrm{dm} 17-1$ & Progeny of sh/wx cross \\
\hline ksh20 & 12 wsh $4-2$ & Jubilee & ksh67 & $12 \mathrm{dm} 18-1$ & Progeny of sh/wx cross \\
\hline ksh21 & 12 wsh $4-3$ & Jubilee & ksh68 & $12 \mathrm{dm} 18-2$ & Progeny of sh/wx cross \\
\hline ksh22 & 12 wsh $4-4$ & Jubilee & ksh69 & $12 \mathrm{dm} 22-1$ & Progeny of sh/wx cross \\
\hline ksh23 & 12 wsh $4-5$ & Jubilee & ksh71 & $12 \mathrm{dm} 25-1$ & Progeny of sh/wx cross \\
\hline ksh24 & 12wsh 5-1 & Jubilee & ksh72 & $12 \mathrm{dm} 32-1$ & Progeny of sh/wx cross \\
\hline ksh25 & 12wsh 5-2 & Jubilee & $\mathrm{ksh} 73$ & $12 \mathrm{dm} 33-1$ & Progeny of sh/wx cross \\
\hline ksh26 & 12 wsh $5-3$ & Jubilee & $\mathrm{ksh} 74$ & $12 \mathrm{dm} 36-1$ & Progeny of sh/wx cross \\
\hline ksh27 & 12wsh 5-4 & Jubilee & ksh75 & $12 \mathrm{dm} 37-1$ & Progeny of sh/wx cross \\
\hline ksh28 & 12 wsh $5-5$ & Jubilee & ksh76 & $12 \mathrm{dm} 38-1$ & Progeny of sh/wx cross \\
\hline ksh29 & 12wsh 5-6 & Jubilee & $\mathrm{ksh} 77$ & $12 \mathrm{dm} 38-2$ & Progeny of sh/wx cross \\
\hline ksh30 & 12wsh 5-7 & Jubilee & ksh78 & $12 \mathrm{dm} 39-1$ & Progeny of sh/wx cross \\
\hline ksh31 & 12 wsh $5-8$ & Jubilee & ksh79 & $12 \mathrm{dm} 39-2$ & Progeny of sh/wx cross \\
\hline ksh32 & 12 wsh $5-9$ & Jubilee & ksh80 & $12 \mathrm{dm} 45-1$ & Progeny of sh/wx cross \\
\hline ksh33 & 12wsh 6-1 & Jubilee & ksh81 & $12 \mathrm{dm} 46-1$ & Progeny of sh/wx cross \\
\hline ksh34 & 12wsh 6-2 & Jubilee & ksh82 & $12 \mathrm{dm} 47-2$ & Progeny of sh/wx cross \\
\hline ksh35 & 12 wsh 6-3 & Jubilee & ksh83 & $12 \mathrm{dm} 47-3$ & Progeny of sh/wx cross \\
\hline $\mathrm{ksh} 36$ & 12 wsh $7-1$ & Jubilee & ksh86 & $12 \mathrm{dm} 67-1$ & Progeny of sh/wx cross \\
\hline ksh37 & 12 wsh $7-2$ & Jubilee & ksh87 & $12 \mathrm{dm} 73-1$ & Progeny of sh/wx cross \\
\hline ksh40 & 12 wsh $7-5$ & Jubilee & ksh88 & $12 \mathrm{dm} 80-1$ & Progeny of sh/wx cross \\
\hline ksh41 & 12 wsh 8-1 & Jubilee & ksh89 & $12 \mathrm{dm} 80-2$ & Progeny of sh/wx cross \\
\hline ksh42 & 12 wsh $8-2$ & Jubilee & ksh91 & $12 \mathrm{dm} 93-1$ & Progeny of sh/wx cross \\
\hline ksh43 & 12 wsh $8-3$ & Jubilee & ksh92 & $12 \mathrm{dm} 95-1$ & Progeny of sh/wx cross \\
\hline ksh44 & 12wsh 9-1 & Jubilee & ksh93 & $12 \mathrm{dm} 98-1$ & Progeny of sh/wx cross \\
\hline ksh45 & 12wsh 9-2 & Jubilee & ksh94 & $12 \mathrm{dm} 99-1$ & Progeny of sh/wx cross \\
\hline ksh46 & 12 wsh $9-3$ & Jubilee & ksh95 & $12 \mathrm{dm} 100-2$ & Progeny of sh/wx cross \\
\hline ksh47 & 12 wsh $9-4$ & Jubilee & ksh96 & $12 \mathrm{dm} 101-1$ & Progeny of sh/wx cross \\
\hline ksh48 & 12 wsh $9-5$ & Jubilee & ksh97 & $12 \mathrm{dm} 102-1$ & Progeny of sh/wx cross \\
\hline ksh49 & 12 wsh 9-6 & Jubilee & ksh98 & $12 \mathrm{dm} 102-2$ & Progeny of sh/wx cross \\
\hline ksh50 & $12 \mathrm{w} 10 \mathrm{~B}-1$ & Progeny of sh/wx cross & ksh100 & $12 \mathrm{dm} 103-3$ & Progeny of sh/wx cross \\
\hline ksh51 & $12 \mathrm{w} 10 \mathrm{~B}-2$ & Progeny of sh/wx cross & & & \\
\hline
\end{tabular}

\section{Electrophoresis and fragment detection}

The final reaction product $(5 \mu \mathrm{L})$ was mixed with $10 \mu \mathrm{L}$ electrophoresis loading buffer (98\% formamide, $0.02 \% \mathrm{BPH}, 0.02 \%$ Xylene $\mathrm{C}$, and $5 \mathrm{mM} \mathrm{NaOH}$ ). After denaturation and immediate 
cooling, $2 \mu \mathrm{L}$ sample was loaded on a $6 \%$ denaturing ( $7.5 \mathrm{M}$ urea) acrylamide-bisacrylamide gel (19:1) in $1 \mathrm{X}$ TBE buffer, and electrophoresed at $1800 \mathrm{~V}$ and $60 \mathrm{~W}$ for $120 \mathrm{~min}$. The separated fragments were visualized using a silver-staining kit (Promega, USA).

\section{Data analyses}

Fragments amplified with SSR primers and SSAP primer combinations were scored according to the presence (1) or absence (0) of each fragment. For SSAP markers, non-polymorphic fragments were eliminated and only polymorphic fragments were scored. The genetic diversity of SSR and SSAP markers was calculated using the POPGENE software (Yeh et al., 1997). Genetic similarities (GS) were calculated for each pair of lines using the Dice similarity index (Dice, 1945). The similarity matrix was then used to construct a dendrogram using the UPGMA (unweighted pair group method using arithmetic average) algorithm from the SAHN option of the NTSYS-pc software (version 2.1) (Rohlf, 1998).

To analyze the genetic population structure of the 87 super sweet corn inbred lines using SSR and SSAP markers, the model-based program STRUCTURE 2.2 (Pritchard and Wen, 2003) was used. The program was run five times for each $K$ value, ranging from 1 to 10 , using the admixture model with a burn-in of 100,000 and a run length of 100,000. An average log likelihood value, $\operatorname{LnP}(\mathrm{D})$, across all runs was calculated for each $\mathrm{K}$. However, the estimated log probability of the data overestimated the number of subgroups. Therefore, to determine the most probable $K$ value, the ad hoc criterion ( $\Delta \mathrm{K}$ ) proposed by Evanno et al. (2005) was used. The estimated number of subgroups showing maximum likelihood was used to assign inbred lines with membership probabilities ${ }^{3} 0.80$ to subgroups. Inbred lines with membership probabilities $<0.80$ were assigned to the admixed group (Wang et al., 2008).

\section{RESULTS}

\section{Genetic variation and diversity}

To confirm the genetic diversity of the 87 super sweet corn inbred lines, 50 SSR and 10 SSAP primer combinations were used. For SSR markers, the 50 SSR primers detected a total of 149 alleles. The number of alleles per locus ranged from 2 to 7 , and the average number of alleles per locus was 2.98. The average effective number of alleles was 1.967, ranging between 1.051 and 4.433. In addition, gene diversity ranged between 0.048 and 0.774 , and was on average 0.441 . The average Shannon's information index was 0.748 varying between 0.116 and 1.665 (Table 2). For SSAP markers, the 10 SSAP primer combinations amplified 322 polymorphic loci in the studied inbred lines. The number of polymorphic loci per primer combination ranged from 26 to 40 , and the average number of loci was 32.2. The average effective number of alleles was 1.602 , ranging between 1.514 and 1.692. Gene diversity ranged from 0.309 to 0.396 with an average of 0.349 . The average Shannon's information index was 0.522 , varying between 0.473 and 0.580 (Table 3 ). To understand the genetic variation in the two subgroups (Jubilee variety and the cross between sh and wx) and the difference between the use of each marker (SSR and SSAP), number of alleles, effective number of alleles, gene diversity, and Shannon's information index were also analyzed in each subgroup (Tables 2 and 3 ). Using the 50 SSR markers, the average number of alleles was 2.80 and 2.70 in groups I and II, respectively. The average effective number of alleles, gene diversity, and Shannon's information index were, respectively, 1.871, 0.419, and 0.703 in group I, and 1.909, 0.417, 
W.R. Ko et al.

and 0.692 in group II (Table 2). However, for the 10 SSAP primer combinations, values of average effective number of alleles, gene diversity, and Shannon's information index were lower (respectively, $1.579,0.335$, and 0.500 in group I, and 1.570, 0.332, and 0.498 ingroup II) (Table 3).

Table 2. Genetic diversity index for 50 SSR loci in the 87 super sweet corn inbred lines.

\begin{tabular}{|c|c|c|c|c|c|c|c|c|c|c|c|c|c|}
\hline \multirow[t]{2}{*}{ SSR loci } & \multirow[t]{2}{*}{ Chr. } & \multicolumn{4}{|c|}{ All $(\mathrm{N}=87)$} & \multicolumn{4}{|c|}{ Jubilee group $(\mathrm{N}=42)$} & \multicolumn{4}{|c|}{$\operatorname{sh} / w x$ group $(\mathrm{N}=45)$} \\
\hline & & $N_{\mathrm{A}}$ & $N_{\mathrm{E}}$ & $\mathrm{h}$ & 1 & $N_{\mathrm{A}}$ & $N_{\mathrm{E}}$ & $\mathrm{h}$ & 1 & $N_{\mathrm{A}}$ & $N_{\mathrm{E}}$ & $\mathrm{h}$ & 1 \\
\hline umc1883 & 1 & 3 & 2.45 & 0.592 & 0.989 & 3 & 2.673 & 0.626 & 1.03 & 3 & 2.076 & 0.518 & 0.893 \\
\hline umc1991 & 1 & 2 & 1.768 & 0.434 & 0.626 & 2 & 1.989 & 0.497 & 0.691 & 2 & 1.385 & 0.278 & 0.451 \\
\hline umc2100 & 1 & 2 & 1.667 & 0.4 & 0.589 & 2 & 1.893 & 0.472 & 0.665 & 2 & 1.335 & 0.251 & 0.418 \\
\hline umc1862 & 1 & 4 & 3.076 & 0.675 & 1.204 & 4 & 3.306 & 0.698 & 1.274 & 3 & 2.837 & 0.648 & 1.069 \\
\hline umc1403 & 1 & 4 & 2.58 & 0.612 & 1.094 & 4 & 2.204 & 0.546 & 1.018 & 3 & 2.904 & 0.656 & 1.082 \\
\hline umc1024 & 2 & 3 & 1.824 & 0.452 & 0.714 & 3 & 2.066 & 0.516 & 0.783 & 3 & 1.501 & 0.334 & 0.578 \\
\hline umc2246 & 2 & 7 & 4.433 & 0.774 & 1.665 & 5 & 3.903 & 0.744 & 1.461 & 7 & 3.148 & 0.682 & 1.399 \\
\hline umc1265 & 2 & 3 & 1.957 & 0.489 & 0.823 & 2 & 1.842 & 0.457 & 0.65 & 3 & 1.968 & 0.492 & 0.856 \\
\hline umc1756 & 2 & 4 & 2.308 & 0.567 & 1.055 & 4 & 2.158 & 0.537 & 0.915 & 4 & 2.187 & 0.543 & 0.998 \\
\hline umc1581 & 2 & 2 & 1.051 & 0.048 & 0.116 & 2 & 1.05 & 0.048 & 0.115 & 2 & 1.051 & 0.049 & 0.117 \\
\hline umc1644 & 3 & 4 & 2.083 & 0.52 & 0.953 & 3 & 1.507 & 0.336 & 0.633 & 4 & 2.714 & 0.632 & 1.139 \\
\hline umc1528 & 3 & 3 & 1.72 & 0.419 & 0.723 & 3 & 1.982 & 0.496 & 0.854 & 2 & 1.499 & 0.333 & 0.515 \\
\hline umc1814 & 3 & 2 & 1.272 & 0.214 & 0.37 & 2 & 1.434 & 0.302 & 0.48 & 2 & 1.136 & 0.12 & 0.238 \\
\hline umc1183 & 3 & 2 & 1.211 & 0.174 & 0.317 & 2 & 1.05 & 0.048 & 0.115 & 2 & 1.385 & 0.278 & 0.451 \\
\hline umc1030 & 3 & 5 & 2.352 & 0.575 & 1.079 & 4 & 2.16 & 0.537 & 0.94 & 4 & 2.321 & 0.569 & 1.015 \\
\hline umc2041 & 4 & 3 & 2.11 & 0.526 & 0.846 & 3 & 1.782 & 0.439 & 0.759 & 3 & 2.188 & 0.543 & 0.849 \\
\hline umc1652 & 4 & 2 & 1.69 & 0.408 & 0.598 & 2 & 1.502 & 0.334 & 0.517 & 2 & 1.838 & 0.456 & 0.648 \\
\hline umc2137 & 4 & 3 & 1.146 & 0.127 & 0.29 & 3 & 1.201 & 0.167 & 0.363 & 2 & 1.097 & 0.089 & 0.188 \\
\hline umc1550 & 4 & 5 & 2.012 & 0.503 & 1.046 & 4 & 1.528 & 0.345 & 0.657 & 5 & 2.516 & 0.603 & 1.208 \\
\hline umc1707 & 4 & 3 & 2.292 & 0.564 & 0.949 & 3 & 1.8 & 0.444 & 0.78 & 3 & 2.731 & 0.634 & 1.049 \\
\hline umc1447 & 5 & 3 & 2.182 & 0.542 & 0.922 & 3 & 2.067 & 0.516 & 0.785 & 3 & 1.847 & 0.459 & 0.756 \\
\hline umc1468 & 5 & 2 & 1.959 & 0.49 & 0.683 & 2 & 2 & 0.5 & 0.693 & 2 & 1.856 & 0.461 & 0.654 \\
\hline umc1852 & 5 & 4 & 1.661 & 0.398 & 0.762 & 4 & 1.95 & 0.487 & 0.93 & 3 & 1.43 & 0.301 & 0.539 \\
\hline umc1224 & 5 & 2 & 1.307 & 0.235 & 0.397 & 2 & 1.699 & 0.411 & 0.602 & 1 & 1 & 0 & 0 \\
\hline umc1752 & 5 & 2 & 1.737 & 0.424 & 0.616 & 2 & 1.125 & 0.111 & 0.224 & 2 & 1.995 & 0.499 & 0.692 \\
\hline umc1887 & 6 & 3 & 1.158 & 0.136 & 0.296 & 3 & 1.336 & 0.251 & 0.482 & 1 & 1 & 0 & 0 \\
\hline umc1341 & 6 & 3 & 2.461 & 0.594 & 0.972 & 3 & 1.898 & 0.473 & 0.804 & 3 & 2.465 & 0.594 & 0.992 \\
\hline umc1595 & 6 & 2 & 1.149 & 0.13 & 0.253 & 2 & 1.303 & 0.232 & 0.394 & 1 & 1 & 0 & 0 \\
\hline umc2056 & 6 & 2 & 1.97 & 0.492 & 0.686 & 2 & 1.998 & 0.5 & 0.693 & 2 & 1.915 & 0.478 & 0.671 \\
\hline umc1388 & 6 & 2 & 1.873 & 0.466 & 0.659 & 2 & 1.995 & 0.499 & 0.692 & 2 & 1.581 & 0.367 & 0.554 \\
\hline umc1134 & 7 & 4 & 2.036 & 0.509 & 0.875 & 4 & 1.909 & 0.476 & 0.868 & 4 & 2.094 & 0.523 & 0.854 \\
\hline umc2334 & 7 & 2 & 1.982 & 0.496 & 0.689 & 2 & 1.832 & 0.454 & 0.647 & 2 & 1.989 & 0.497 & 0.691 \\
\hline phi051 & 7 & 3 & 2.138 & 0.532 & 0.869 & 2 & 1.498 & 0.332 & 0.515 & 3 & 2.565 & 0.61 & 1 \\
\hline umc1324 & 7 & 2 & 1.415 & 0.293 & 0.469 & 2 & 1.536 & 0.349 & 0.533 & 2 & 1.308 & 0.236 & 0.398 \\
\hline umc1450 & 7 & 3 & 1.895 & 0.472 & 0.811 & 3 & 1.616 & 0.381 & 0.694 & 3 & 2.148 & 0.534 & 0.887 \\
\hline umc1627 & 8 & 3 & 1.913 & 0.477 & 0.825 & 3 & 2.243 & 0.554 & 0.942 & 2 & 1.568 & 0.362 & 0.548 \\
\hline umc2075 & 8 & 2 & 1.246 & 0.198 & 0.349 & 2 & 1.273 & 0.214 & 0.371 & 2 & 1.22 & 0.18 & 0.325 \\
\hline umc1904 & 8 & 2 & 1.575 & 0.365 & 0.551 & 2 & 1.254 & 0.202 & 0.355 & 2 & 1.825 & 0.452 & 0.644 \\
\hline umc1360 & 8 & 3 & 1.229 & 0.187 & 0.393 & 3 & 1.219 & 0.18 & 0.375 & 3 & 1.239 & 0.193 & 0.407 \\
\hline umc1913 & 8 & 4 & 2.598 & 0.615 & 1.096 & 4 & 2.111 & 0.526 & 1.01 & 3 & 2.15 & 0.535 & 0.877 \\
\hline umc1094 & 9 & 4 & 2.844 & 0.648 & 1.154 & 3 & 2.477 & 0.596 & 0.988 & 4 & 2.758 & 0.638 & 1.141 \\
\hline umc1634 & 9 & 3 & 2.848 & 0.649 & 1.071 & 3 & 2.384 & 0.581 & 0.977 & 3 & 2.699 & 0.63 & 1.045 \\
\hline umc2338 & 9 & 3 & 1.052 & 0.05 & 0.132 & 2 & 1.026 & 0.025 & 0.069 & 2 & 1.078 & 0.072 & 0.16 \\
\hline umc1867 & 9 & 3 & 2.248 & 0.555 & 0.914 & 3 & 2.317 & 0.568 & 0.926 & 3 & 2.174 & 0.54 & 0.898 \\
\hline umc1107 & 9 & 2 & 1.949 & 0.487 & 0.68 & 2 & 1.876 & 0.467 & 0.66 & 2 & 1.988 & 0.497 & 0.69 \\
\hline umc1176 & 10 & 3 & 2.262 & 0.558 & 0.889 & 3 & 2.339 & 0.572 & 0.946 & 3 & 2.024 & 0.506 & 0.747 \\
\hline umc1336 & 10 & 3 & 2.579 & 0.612 & 1.012 & 3 & 2.222 & 0.55 & 0.92 & 3 & 2.806 & 0.644 & 1.061 \\
\hline umc1785 & 10 & 3 & 2.918 & 0.657 & 1.084 & 3 & 2.774 & 0.64 & 1.058 & 3 & 2.817 & 0.645 & 1.068 \\
\hline umc2053 & 10 & 2 & 1.471 & 0.32 & 0.5 & 2 & 1.354 & 0.262 & 0.431 & 2 & 1.585 & 0.369 & 0.556 \\
\hline umc2016 & 10 & 4 & 1.68 & 0.405 & 0.735 & 4 & 1.893 & 0.472 & 0.863 & 3 & 1.501 & 0.334 & 0.578 \\
\hline Mean & 2.98 & 1.967 & 0.441 & 0.748 & 2.80 & 1.871 & 0.419 & 0.703 & 2.70 & 1.909 & 0.417 & 0.692 & \\
\hline SD & 1.02 & 0.631 & 0.175 & 0.314 & 0.81 & 0.562 & 0.17 & 0.29 & 1.04 & 0.603 & 0.2 & 0.343 & \\
\hline Min. & 2 & 1.051 & 0.048 & 0.116 & 2 & 1.026 & 0.025 & 0.069 & 1 & 1 & 0 & 0 & \\
\hline Max. & 7 & 4.433 & 0.774 & 1.665 & 5 & 3.903 & 0.744 & 1.461 & 7 & 3.148 & 0.682 & 1.399 & \\
\hline
\end{tabular}

$N_{\mathrm{A}}=$ observed number of alleles; $N_{\mathrm{E}}=$ effective number of alleles; $\mathrm{h}=$ Nei's (1973) gene diversity; I = Shannon's information index. 
Table 3. Genetic diversity index for 10 SSAP primer combinations in the 87 super sweet corn inbred lines.

\begin{tabular}{|c|c|c|c|c|c|c|c|c|c|c|}
\hline \multirow{2}{*}{$\begin{array}{l}\text { Primer } \\
\text { Combination }\end{array}$} & \multirow[b]{2}{*}{$\mathrm{PL}^{*}$} & \multicolumn{3}{|c|}{ All $(N=87)$} & \multicolumn{3}{|c|}{ Jubilee group $(\mathrm{N}=42)$} & \multicolumn{3}{|c|}{ sh/wx group $(\mathrm{N}=45)$} \\
\hline & & $N_{\mathrm{E}}$ & $\mathrm{h}$ & 1 & $N_{\mathrm{E}}$ & $\mathrm{h}$ & I & $N_{\mathrm{E}}$ & $\mathrm{h}$ & 1 \\
\hline $\begin{array}{l}\text { JiATA } \\
\text { ATA }\end{array}$ & 30 & 1.517 & 0.322 & 0.494 & 1.53 & 0.318 & 0.48 & 1.486 & 0.297 & 0.456 \\
\hline Ji1CGG & 26 & 1.539 & 0.316 & 0.477 & 1.533 & 0.318 & 0.483 & 1.463 & 0.281 & 0.429 \\
\hline Ji1CGT & 35 & 1.608 & 0.349 & 0.52 & 1.524 & 0.299 & 0.448 & 1.605 & 0.351 & 0.522 \\
\hline Op2ATA & 39 & 1.65 & 0.364 & 0.535 & 1.586 & 0.332 & 0.491 & 1.634 & 0.361 & 0.533 \\
\hline Op2CGG & 28 & 1.602 & 0.354 & 0.528 & 1.647 & 0.365 & 0.539 & 1.495 & 0.303 & 0.463 \\
\hline Op2ATG & 26 & 1.692 & 0.396 & 0.58 & 1.679 & 0.385 & 0.566 & 1.66 & 0.369 & 0.543 \\
\hline Op1ATG & 32 & 1.586 & 0.347 & 0.522 & 1.561 & 0.337 & 0.511 & 1.565 & 0.333 & 0.503 \\
\hline Op1CGT & 29 & 1.625 & 0.358 & 0.531 & 1.573 & 0.332 & 0.496 & 1.63 & 0.362 & 0.536 \\
\hline Ji2CGT & 40 & 1.514 & 0.309 & 0.473 & 1.516 & 0.303 & 0.457 & 1.487 & 0.293 & 0.448 \\
\hline Ji2ATG & 37 & 1.689 & 0.383 & 0.56 & 1.664 & 0.376 & 0.554 & 1.651 & 0.365 & 0.537 \\
\hline Mean & 32.2 & 1.602 & 0.349 & 0.522 & 1.579 & 0.335 & 0.5 & 1.57 & 0.332 & 0.498 \\
\hline SD & & 0.311 & 0.139 & 0.17 & 0.33 & 0.154 & 0.196 & 0.323 & 0.151 & 0.192 \\
\hline Min. & 26 & 1.514 & 0.309 & 0.473 & 1.516 & 0.299 & 0.448 & 1.463 & 0.281 & 0.429 \\
\hline Max. & 40 & 1.692 & 0.396 & 0.580 & 1.679 & 0.385 & 0.566 & 1.66 & 0.369 & 0.543 \\
\hline
\end{tabular}

*Number of polymorphic loci in each primer combination.

\section{Genetic relationship and population structure}

To assess the genetic relationship and population structure of the 87 inbred lines using SSR and SSAP markers, as well as to characterize the two subgroups (Jubilee and sh/wx), three independent GS matrices of SSR, SSAP, and combined marker data were constructed based on all lines, comparison among groups, and comparison between groups (Table 4). The GS of all inbred lines calculated with the SSR data showed an average of 52.3, ranging from 18.2 to 94.9. The GS among groups was 54.7 and 53.0 for Jubilee and sh/wx groups, respectively. The GS between groups was 50.8. Considering all inbred lines, the GS calculated with the SSAP data was 56.0 and ranged between 32.6 and 88.6. The GS among groups was 55.8 and 59.0 for Jubilee and sh/wx groups, respectively. The GS between groups was 54.5. In addition, the GS of all inbred lines generated by the combined marker data was 55.0 and ranged between 36.4 and 88.3. The GS among groups was 55.5 and 57.5 for Jubilee and sh/wx groups, respectively, whereas the GS between groups was 53.6.

Table 4. Genetic similarities calculated from SSR, SSAP, and combined data for a combination of all lines and different groups.

\begin{tabular}{|c|c|c|c|c|c|c|c|c|c|c|c|c|c|}
\hline \multirow[t]{2}{*}{ Combination } & \multirow[b]{2}{*}{$(\mathrm{N})$} & \multicolumn{4}{|c|}{ SSR marker } & \multicolumn{4}{|c|}{ SSAP marker } & \multicolumn{4}{|c|}{ Combine data } \\
\hline & & Mean & Min. & Max. & $\mathrm{SD}$ & Mean & Min. & Max. & SD & Mean & Min. & Max. & SD \\
\hline Among all & 3741 & 52.3 & 18.2 & 94.9 & 9.3 & 56.0 & 32.6 & 88.6 & 7.0 & 55.0 & 36.4 & 88.3 & 6.8 \\
\hline Jubilee $v s$ sh/wx & 1890 & 50.8 & 18.2 & 78.7 & 8.2 & 54.5 & 32.6 & 76.5 & 6.0 & 53.6 & 36.4 & 77.1 & 5.7 \\
\hline Jubilee vs Jubilee & 861 & 54.7 & 20.7 & 94.9 & 10.2 & 55.8 & 39.2 & 88.0 & 7.2 & 55.5 & 38.2 & 88.3 & 7.5 \\
\hline$s h / w x$ vs sh/wx & 990 & 53.0 & 25.0 & 93.9 & 9.9 & 59.0 & 42.1 & 88.6 & 7.6 & 57.5 & 41.2 & 87.8 & 7.4 \\
\hline
\end{tabular}

Dendrograms were constructed based on the similarity values resulting from SSR, SSAP, and combined marker data. The dendrogram using SSR marker data showed a complex pattern with nine clusters and a GS value of $53.0 \%$ (Figure 1A). Group I only contained 1 accession (ksh3), group II accounted for 52 accessions (24 inbred lines of Jubilee and 28 of sh/wx), group III contained 9 accessions (all of Jubilee), group IV contained 7 accessions ( 3 of Jubilee and 4 of sh/wx), group $V$ contained 10 accessions (all of sh/wx), group VI contained 5 accessions (all of 
Jubilee), and groups VII, VIII, and IX contained 1 accession of the Jubilee group. The dendrogram with SSAP marker data showed three main clusters with a GS of $50.8 \%$ (Figure 1B). Group I accounted for 3 accessions (all of Jubilee), group II contained 74 accessions (39 inbred lines of Jubilee and 35 of sh/wx), and group III contained 10 accessions (all of sh/wx). To achieve more detail on the genetic relationship between subgroups, the combined data of SSR and SSAP markers was also analyzed. A total of six clusters were detected with a GS of $53.5 \%$ (Figure $1 \mathrm{C}$ ). Group I contained 1 accession of the Jubilee group, group II contained 66 accessions (31 inbred lines of Jubilee and 35 of sh/wx), group III contained 7 accessions of the Jubilee group, group IV contained only 1 accession (ksh19), group $V$ contained 10 accessions of the sh/wx group, and group VI contained 2 accessions of the Jubilee group.

A

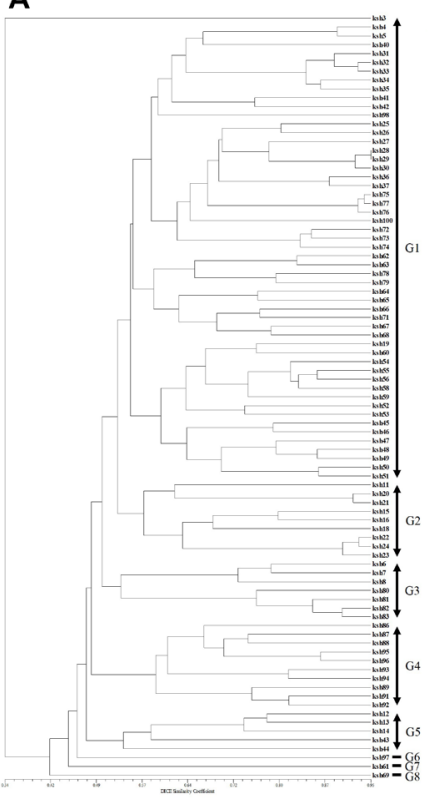

B

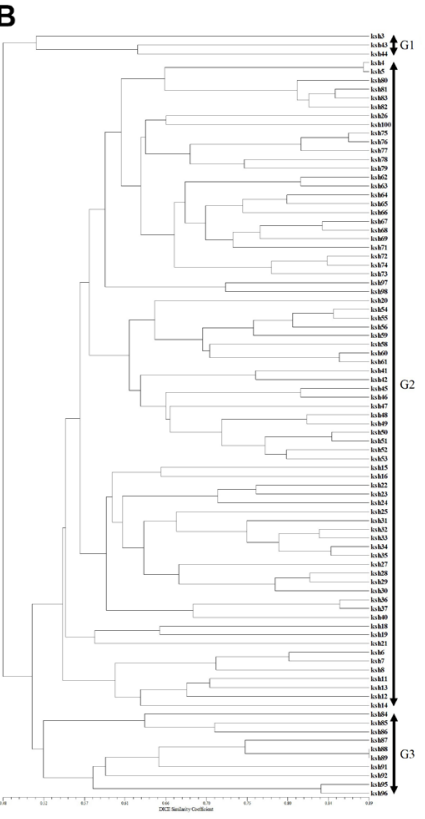

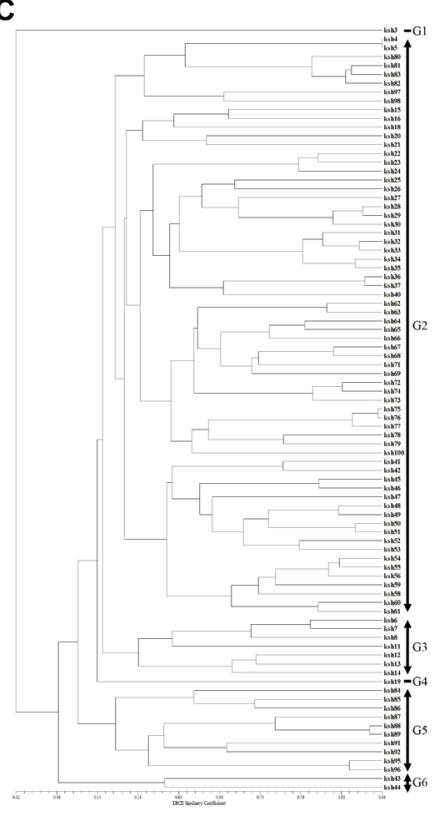

Figure 1. UPGMA dendrogram based on the SSR (A), SSAP (B), and combined data (C).

To analyze genetic population structure, the STRUCTURE software program was used for SSR, SSAP, and combined data. To estimate the number of subgroups, the $\Delta \mathrm{K}$ value was used following Evanno et al. (2005). Moreover, each subgroup was determined based on the membership probability threshold of 0.8 (Wang et al., 2008). The highest $\Delta \mathrm{K}$ value based on SSR markers was $K=2$. Based on the membership probability, total inbred lines were divided into groups I, II, and admixed (Figure 2A). A total of 43 accessions (22 inbred lines of Jubilee and 21 of sh/wx) with a membership lower than 0.8 were assigned to group I, 27 (12 inbred lines of Jubilee and 15 of sh/wx) to group II, and 17 (8 inbred lines of Jubilee and 9 of sh/wx) to the admixed group. The highest $\Delta K$ value based on SSAP marker data was also $K=2$. Inbred lines were divided into groups I, II, and admixed. Group I contained 11 accessions (5 inbred lines of Jubilee and 6 of sh/ $w x$ ), group II contained 59 accessions (26 inbred lines of Jubilee and 33 of sh/wx), and the admixed group contained 17 accessions (11 inbred lines of Jubilee and 6 of sh/wx) (Figure 2B). However, 
analyzing population structure using combined marker data resulted in $\mathrm{K}=3$. A slightly different pattern was observed, whereby inbred lines were divided into groups I, II, III, and admixed (Figure 2C). A total of 14 accessions (1 inbred line of Jubilee and 13 of sh/wx) were assigned to group I, 30 to group II (17 inbred lines of Jubilee and 13 of sh/wx), and 8 to group III (4 inbred lines of each group). The remaining 35 accessions (20 inbred lines of Jubilee and 15 of sh/wx) were assigned to the admixed group.

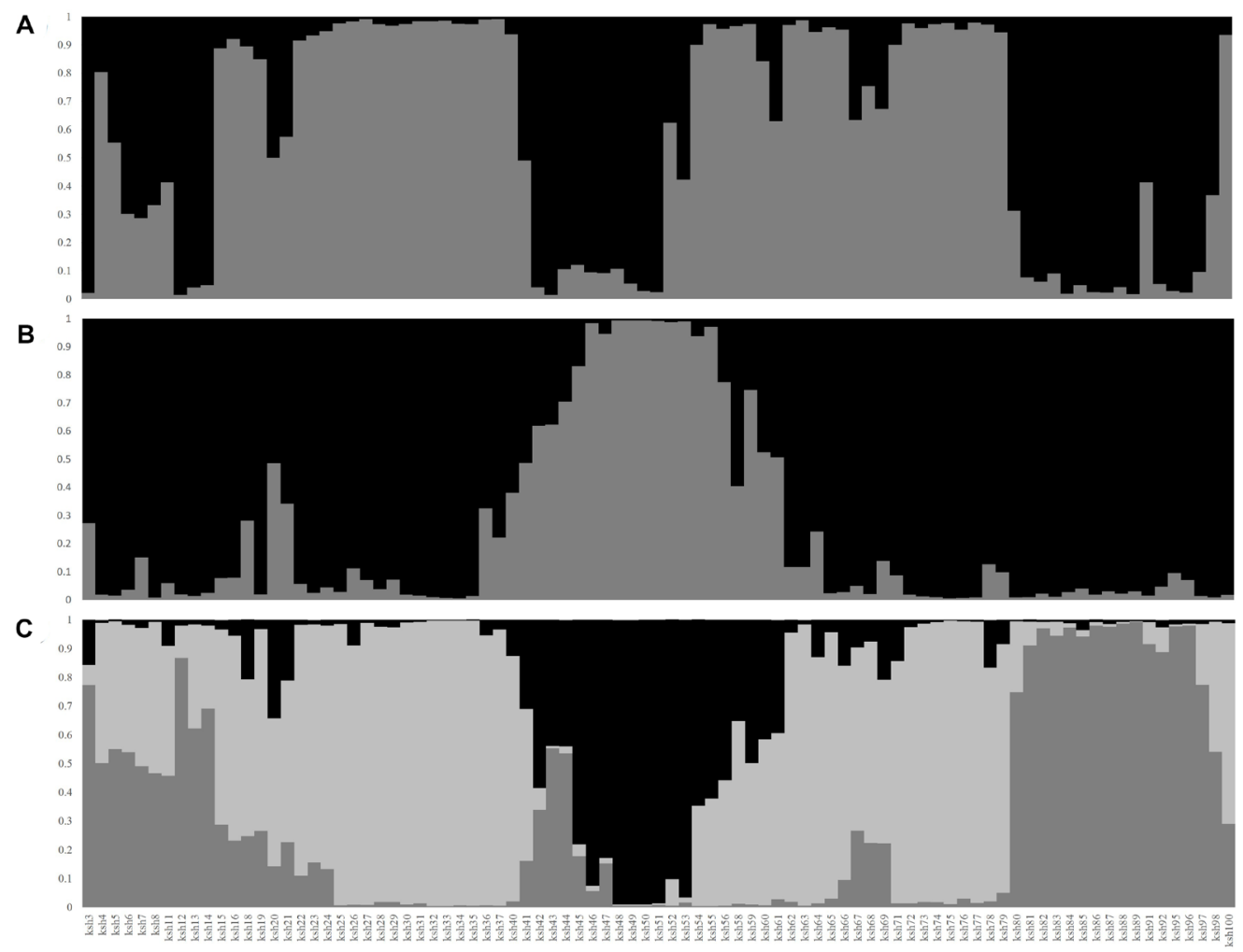

Figure 2. Population structure based on the SSR (A), SSAP (B), and combined data (C).

\section{DISCUSSION}

Various molecular markers have been developed for plant molecular breeding (Biswas et al., 2011). Advances in molecular marker techniques allow the detection of genetic variation and diversity at the molecular level. Information on the genetic diversity, genetic relationship, and population structure is useful for the development of new cultivars or elite inbred lines in maizebreeding programs. Although various marker systems have already been developed and applied in plant breeding, some markers are more appropriate than others for specific applications (Biswas et al., 2011). Therefore, it is important to select an appropriate marker system according to the intended application. A better understanding of the efficiency of different markers is considered an important step towards germplasm classification and characterization (Belaj et al., 2003). In this study, 50 SSR and 10 SSAP markers were used to analyze the genetic diversity, genetic 
relationship, and population structure of 87 super sweet corn inbred lines originating from two different varieties (Jubilee and progenies of a cross between sh and wx). The average gene diversity and Shannon's information index using SSR markers were 0.441 and 0.748 , respectively (Table 2). The average gene diversity and Shannon's information index using SSAP markers were 0.349 and 0.522 , respectively (Table 3 ). These results show that the genetic diversity of SSR markers is much higher than that of SSAP markers. This is in agreement with other studies, which compare different markers (Belaj et al., 2003; Biswas et al., 2011). It seems that SSR markers have a higher mutation rate and more alleles per locus than SSAP markers. Although SSAP markers have lower costs due to the large number of loci analyzed per assay (Tam et al., 2005), SSR markers are more appropriate to study the genetic diversity of corn inbred lines. In addition, the experimental procedure using SSR markers is easier and faster than that of SSAP markers. It was expected that Jubilee and sh/wx populations would have low genetic diversity due to their limited population size. In a previous study using 40 waxy and 40 normal maize varieties, genetic diversity was, respectively, 0.592 and 0.642 (Sa et al., 2011). Although a similar number of inbred lines were used in this study, the genetic diversity was remarkably lower than that observed in the previous study, which corresponded with expectations. The present study also compared the genetic diversity among two subgroups originating from the Jubilee and sh/wx groups. Using SSR markers, the average number of alleles, gene diversity, and Shannon's information index were, respectively, 2.80, 0.419, and 0.703 in the Jubilee group, and 2.70, 0.417, and 0.692 in the sh/wx group (Table 2). Using SSAP markers, results showed a similar pattern, pointing out that although the number of inbred lines was lower in the Jubilee group $(N=42)$ than in the sh/wx group $(N=$ 45), the genetic diversity index of the Jubilee group was slightly higher than that of the sh/wx group.

Understanding the genetic diversity and relationship of inbred lines is very important and is a prerequisite for the conservation and efficient use of germplasm for crop breeding (Laidò et al., 2013). This study also analyzed the genetic relationship of the 87 inbred lines using SSR, SSAP, and combined marker data. Eight, three, and six clusters were generated using SSR, SSAP, and combined marker data, respectively. However, all groups were not classified according to their origin. This study also compared SSR, SSAP, and combined marker data in each group within the different subgroups (Figure 1). For clusters based in SSR markers, all groups except groups II and IV were well clustered. Group II was divided into three subgroups and had a GS of 55.0\%. Although the accessions of subgroup 2 clustered with only one progeny of the sh/wx group, subgroups 1 and 3 did not cluster according to their origin. Group IV was divided into two subgroups with a GS of $53.5 \%$, which were well divided into Jubilee and sh/wx groups. The three clusters based in SSAP markers were divided into one large group (II) and two small groups (I and III). Groups I and III were well divided according to their origin, but group II contained five subgroups with a GS of $57.5 \%$. Subgroups 3, 4, and 5 of group II were only clustered with accessions of the Jubilee group. Although the accessions of subgroups 1 and 2 did not permit a clear identification of their origin, almost all accessions (except a few inbred lines) classified according to their origin. For combined marker data, groups I, III, IV, V, and VI were classified according to their origin. However, group II could not be clearly distinguished from the others and clustered in five subgroups with a GS of $58 \%$. Among these, subgroups II, III, and IV were classified according to their origin but subgroups $\mathrm{I}$ and $\mathrm{V}$ could not be classified. Moreover, this study also analyzed population structure of the 87 super sweet corn inbred lines (Figure 2). However, similarly as for the genetic relationship analysis, the population structure pattern was not clearly distinguished between Jubilee and sh/wx groups for any of the markers used. Population structure in terms of number of inbred lines of a group 
was different between SSR and SSAP markers. Using SSR markers, group I had 43 accessions, whereas using SSAP markers only 11 were found. In relation to group II, 27 accessions were found with SSR and 59 with SSAP markers.

Differences were found in genetic diversity and genetic relationships between SSR and SSAP markers. A low correlation between results obtained using different marker systems has been shown in previous studies (Pejic et al., 1998; Giancola et al., 2002). Some reasons might have contributed to the differences found between SSR and SSAP results. One could be the difference in polymorphisms, since SSR is a co-dominant marker and SSAP a dominant one. Another reason could be the difference in amplified target regions, as SSR markers are repetitive and short DNA motifs, whereas SSAP markers derive from a retrotransposon. In addition, the genetic population structure reflects interactions among plants with regard to their long-term evolutionary history, mutation and recombination, genetic drift, reproductive system, gene flow, and natural selection (Slatkin, 1987; Schaal et al., 1998). The materials in this study were generated from new super sweet corn. Since the two groups derived from the Jubilee variety and from progenies of the cross between sh and wx varieties, low diversity and complex population structure may occur due to selection of similar directions. Therefore, the two markers used are not distinguished in all 87 super sweet corn inbred lines. Super sweet corn is still not popular in Korea, but it is capturing the attention of Korean youth. A systematic study of super sweet corn varieties has limited applications. The 87 super sweet corn inbred lines studied here have shown to be valuable genetic resources for the development of a new super sweet corn cultivar. This study has done a comparative analysis of the use of SSR and SSAP markers for the study of genetic diversity and genetic relationships of super sweet corn inbred lines. Results are useful for maize-breeding programs in Korea.

\section{Conflicts of interest}

The authors declare no conflict of interest.

\section{ACKNOWLEDGMENTS}

Research supported by the Cooperative Research Program for Agriculture Science \& Technology Development (Project title \#PJ01177601, Project \#PJ011776) Rural Development Administration, Republic of Korea, the Golden Seed Project (\#213001-04-1-SBA10), the Ministry of Agriculture, Food, and Rural Affairs (MAFRA), the Ministry of Oceans and Fisheries (MOF), the Rural Development of Korea (RDA), and the Korea Forest Service (KFS).

\section{REFERENCES}

Azanza F, Bar-Zur A and Juvik JA (1996). Variation in sweet corn kernel characteristics associated with stand establishment and eating quality. Euphytica 87: 7-18. http://dx.doi.org/10.1007/BF00022959

Belaj A, Satovic Z, Cipriani G, Baldoni L, et al. (2003). Comparative study of the discriminating capacity of RAPD, AFLP and SSR markers and of their effectiveness in establishing genetic relationships in olive. Theor. Appl. Genet. 107: 736-744. http://dx.doi.org/10.1007/s00122-003-1301-5

Biswas MK, Chai L, Amar MH, Zhng X, et al. (2011). Comparative analysis of genetic diversity in Citrus germplasm collection using AFLP, SSAP, SAMPL and SSR markers. Sci. Hort. 129: 798-803. http://dx.doi.org/10.1016/j.scienta.2011.06.015

Dao A, Sanou J, Mitchell SE, Gracen V, et al. (2014). Genetic diversity among INERA maize inbred lines with single nucleotide polymorphism (SNP) markers and their relationship with CIMMYT, IITA, and temperate lines. BMC Genet. 15: 127. http://dx.doi.org/10.1186/s12863-014-0127-2 
Dellaporta SL, Wood J and Hicks JB (1983). A simple and rapid method for plant DNA preparation. Version II. Plant Mol. Biol. Rep. 1: 19-21. http://dx.doi.org/10.1007/BF02712670

Dice LR (1945). Measures of the amount of ecologic association between species. Ecology 26: 297-302. http://dx.doi.org/10.2307/1932409

Duvick DN, Smith JSC and Cooper RM (2004). Long-term selection in a commercial hybrid maize breeding program. Plant Breed. Rev. 24: 109-151.

El-Hamed KEA, Elwan MWM and Shaban WI (2011). Enhanced sweet corn propagation: studies on transplanting feasibility and seed priming. Veg. Crop. Res. Bull. 75: 31-50.

Enoki H, Sato $\mathrm{H}$ and Koinuma K (2002). SSR analysis of genetic diversity among maize inbred lines adapted to cold regions of Japan. Theor. Appl. Genet. 104: 1270-1277.http://dx.doi.org/10.1007/s00122-001-0857-1

Evanno G, Regnaut S and Goudet J (2005). Detecting the number of clusters of individuals using the software STRUCTURE: a simulation study. Mol. Ecol. 14: 2611-2620.http://dx.doi.org/10.1111/j.1365-294X.2005.02553.x

Giancola S, Marcucci Poltri S, Lacaze P and Hopp HE (2002). Feasibility of integration of molecular markers and morphological descriptors in a real case study of a plant variety protection system for soybean. Euphytica 127: 95-113. http://dx.doi.org/10.1023/A:1019923923805

Hallauer AR, Russell WA and Lamkey KR (1988). Corn breeding. In: Corn and corn improvement (Sprague GF and Dudley JW, eds). 3rd edn. Agron, Monogr. 18, Madison, 463-564.

Hassell RL, Dufault RJ and Phillips TL (2003). Low-temperature germination response of su, se, and $\mathrm{sh}_{2}$ sweet corn cultivars. Hort. Technol. 13:136-141.

Jing R, Vershinin A, Grzebyta J, Shaw P, et al. (2010). The genetic diversity and evolution of field pea (Pisum) studied by high throughput retrotransposon based insertion polymorphism (RBIP) marker analysis. BMC Evol. Biol. 10: 44. http://dx.doi.org/10.1186/1471-2148-10-44

Kalendar R and Schulman AH (2006). IRAP and REMAP for retrotransposon-based genotyping and fingerprinting. Nat. Protoc. 1: 2478-2484.http://dx.doi.org/10.1038/nprot.2006.377 PubMed

Kalendar R, Grob T, Regina M, Suoniemi A, et al. (1999). IRAP and REMAP: two new retrotransposon-based DNA fingerprinting techniques. Theor. Appl. Genet. 98: 704-711. http://dx.doi.org/10.1007/s001220051124

Kashiani P, Saleh G, Panandam JM, Abdullah NAP, et al. (2012). Molecular characterization of tropical sweet corn inbred lines using microsatellite markers. Maydica 57: 154-163.

Kwiatkowski A and Clemente E (2007). Characteristics of sweet corn (Zea mays L.) for industrialization. Ver. Bras. Tecnol. Agro. 1: 93-103.

Laidò G, Mangini G, Taranto F, Gadaleta A, et al. (2013). Genetic diversity and population structure of tetraploid wheats ( Triticum turgidum L.) estimated by SSR, DArT and pedigree data. PLoS One 8: e67280. http://dx.doi.org/10.1371/journal.pone.0067280

Lee SS, Kim TJ and Park JS (1987). Sugar, soluble solids and flavor as influenced by maturity of sweet corn. Korean J. Crop. Sci. 32: 86-91.

Mardi M, Naghavi MR, Pirseyedi SM, Alamooti MK, et al. (2011). Comparative assessment of SSAP, AFLP and SSR markers for evaluation of genetic diversity of durum wheat (Triticum turgidum L. var. durum).J. Agr. Sci. Tech. 13: 905-920.

Marshall SW and Tracy WF (2003). Sweet corn. In: Corn: chemistry and technology (White PJ and JohnsonLA, eds). MN: American Association of Cereal Chemists, St. Paul, 537-569.

Melchinger AE, Boppenmaier J, Dhillon BS, Pollmer WG, et al. (1992). Genetic diversity for RFLPs in European maize inbreds: II. Relation to performance of hybrids within versus between heterotic groups for forage traits. Theor. Appl. Genet. 84: 672-681.

Nei M (1973). Analysis of gene diversity in subdivided populations. Proc. Natl. Acad. Sci. USA 70: 3321-3323. http://dx.doi.org/10.1073/pnas.70.12.3321

Paux E, Faure S, Choulet F, Roger D, et al. (2010). Insertion site-based polymorphism markers open new perspectives for genome saturation and marker-assisted selection in wheat. Plant Biotechnol. J. 8: 196-210. http://dx.doi.org/10.1111/j.1467-7652.2009.00477.x

Pejic I, Marsan PA, Morgante M, Kozumplick V, et al. (1998). Comparative analysis of genetic similarity among maize inbred lines detected by RFLPs, RAPLs, SSRs, and AFLP. Theor. Appl. Genet. 97: 1248-1255. http://dx.doi.org/10.1007/s001220051017

Pritchard JK and Wen W (2003). Documentation for STRUCTURE software: Version 2.

Rafalski JA, Vogel JM, Morgante M, Powell W, et al. (1996). Generating and using DNA markers in plants. In: Non-mammalian genomic analysis (Birren B and Lai E, eds.). A practical guide, San Diego, 75-134.

Rohlf FJ (1998). NTSYS-pc: Numerical taxonomy and multivariate analysis system. Version 2.02. Exeter Software, New York.

Roy NS, Choi JY, Lee SI and Kim NS (2015). Marker utility of transposable elements for plant genetics, breeding, and ecology: a review. Genes Genomics 37:141-151. http://dx.doi.org/10.1007/s13258-014-0252-3 
Russell RJ, Fuller JD, Macaulay M, Hats BG, et al. (1997). Direct comparison of levels of genetic variation among barley accessions detected by RFLPs, AFLPs, SSRs and RAPDs. Theor. Appl. Genet. 95: 714-722. http://dx.doi.org/10.1007/s001220050617

Sa KJ, Kim JA, Park KJ, Park JY, et al. (2011). Analysis of genetic diversity and population structure for core set of waxy and normal maize inbred lines using SSR markers. Korean J. Breed. Sci. 43: 362-373.

Schaal B, Hayworth D, Olsen K, Rauscher J, et al. (1998). Phylogeographic studies in plants: problems and prospects. Mol. Ecol. 7: 465-474. http://dx.doi.org/10.1046/j.1365-294x.1998.00318.x

Slatkin M (1987). Gene flow and the geographic structure of natural populations. Science 236: 787-792. http://dx.doi.org/10.1126/science.3576198

Solomon KF, Zeppa A and Mulugeta SD (2012). Combining ability, genetic diversity and heterosis in relation to $F_{1}$ performance of tropically adapted shrunken (sh2) sweet corn lines. Plant Breed. 131: 430-436. http://dx.doi.org/10.1111/j.1439-0523.2012.01965.x

Tam SM, Mhiri C, Vogelaar A, Kerkveld M, et al. (2005). Comparative analyses of genetic diversities within tomato and pepper collections detected by retrotransposon-based SSAP, AFLP and SSR. Theor. Appl. Genet. 110: 819-831. http://dx.doi.org/10.1007/s00122-004-1837-z

Tracy WF (2001). Sweet corn. In: Specialty corns (HallauerAR, eds.).Boca Raton, 155-199.

Vitte C, Ishii T, Lamy F, Brar D, et al. (2004). Genomic paleontology provides evidence for two distinct origins of Asian rice (Oryza sativa L.). Mol. Genet. Genomics 272: 504-511.http://dx.doi.org/10.1007/s00438-004-1069-6

Wang R, Yu Y, Zhao J, Shi Y, et al. (2008). Population structure and linkage disequilibrium of a mini core set of maize inbred lines in China. Theor. Appl. Genet. 117: 1141-1153.http://dx.doi.org/10.1007/s00122-008-0852-x

Waugh R, McLean K, Flavell AJ, Pearce SR, et al. (1997). Genetic distribution of Bare-1-like retrotransposable elements in the barley genome revealed by sequence-specific amplification polymorphisms (S-SAP). Mol. Gen. Genet. 253: 687-694 http://dx.doi.org/10.1007/s004380050372

Yeh FC, Yang RC, Boyle TBJ, Ye ZH, et al. (1997). POPGENE: the user-friendly shareware for population genetic analysis. Molecular Biology and Biotechnology Center, Alberta. 